\title{
OS EQUÍVOCOS LEGAIS DA FILANTROPIA
}

\author{
Prof. Wanderlei José Ghilardi ${ }^{1}$ \\ Prof. Paulo Sérgio Ceretta ${ }^{2}$
}

\section{RESUMO}

Este artigo procura evidenciar as dificuldades que as entidades filantrópicas enfrentam de desenvolverem suas ações nas áreas da educação e da saúde em função das dificuldades, cada vez maiores, de enquadramento na legislação pertinente. Permanecendo o quadro atual, com as isenções menores do que os encargos de assistência social, muitas entidades começam a fazer contas para saber da viabilidade de serem filantrópicas. Procura-se demonstrar, através de exemplos práticos, a utilização de critérios injustos para a renovação do Certificado de Entidade de Assistência Social, condição para o reconhecimento como entidades filantrópicas. Os resultados obtidos permitem concluir que há equívocos legais, devido à aplicação de um percentual linear para todas as entidades, independentemente da capacidade de geração de receita de cada uma.

\section{INTRODUÇÃO}

A sociedade, de uma forma geral, começa a ter maiores informações sobre a existência e o funcionamento das entidades filantrópicas. Os dados publicados revelam o quanto essas entidades deixam de contribuir por serem consideradas imunes ou isentas dos impostos. O referido benefício fiscal pode ser interpretado como uma forma indireta de a própria sociedade contribuir com aqueles impostos, tornando-se objeto de questionamentos quanto aos critérios de concessão da filantropia e, em contrapartida, os benefícios que as entidades geram à população em geral. Segundo o entendimento de Pozzobon (2003), as entidades filantrópicas são constituídas e registradas para colaborar na missão do

\footnotetext{
${ }^{1}$ Professor do Departamento de Ciências Contábeis da Universidade Federal de Santa Maria.

${ }^{2}$ Professor do Departamento de Administração da Universidade Federal de Santa Maria.
} 
Estado, suprindo as deficiências deste no atendimento de finalidades educacionais, culturais, assistenciais, de saúde, beneficentes e de atividades voltadas para a promoção da pessoa humana e proteção do bem comum, ou seja, para ocupar um papel paraestatal. Por esse motivo, e porque cumprem os requisitos legais, as instituições filantrópicas são reconhecidas pelo Estado como sendo de utilidade pública nas diversas esferas políticas.

Durante algum tempo as entidades foram inscritas no Conselho Nacional de Assistência Social sem qualquer comprovação de tipo, qualidade e quantidade de atendimentos que seriam prestados, interessadas unicamente nos benefícios da imunidade e isenção tributárias. É por esse motivo que consagrou-se no Brasil a designação de "entidades pilantrópicas", derivada de pilantragem, ou entidades de fachada.

Diante de tantas dificuldades, as entidades, que sempre foram beneficentes e de assistência social, começam a fazer as contas sobre as vantagens de ser ou não, também entidade filantrópica.

\section{ENTIDADES FILANTRÓPICAS}

As entidades e organizações de assistência social são definidas pela Lei Orgânica da Assistência Social - LOAS (1997), em seu art. 3. ${ }^{\circ}$ como sendo aquelas que prestam, sem fins lucrativos, atendimento e assessoramento aos beneficiários abrangidos por esta lei, bem como as que atuam na defesa e garantia de seus direitos. A LOAS é a própria Lei n. ${ }^{\circ} 8.742$ (1993), que dispõe sobre a organização da assistência social e regulamenta os artigos 203 e 204 da Constituição Federal, que trata dos destinatários da assistência social e das fontes de financiamento dos recursos respectivamente. Segundo essa Lei, na prestação dos serviços deve ser dada prioridade à infância e à adolescência em situação de risco pessoal e social, atendendo o princípio da universalização dos direitos sociais. Também estabelece que a seguridade será financiada por toda a sociedade, de forma direta e indireta, mediante recursos públicos ou das contribuições previdenciárias e que as ações na área de assistência social são 
organizadas em sistema descentralizado e participativo, constituído pelas entidades e organizações de assistência social por ela abrangidas. Essa mesma Lei, em seu artigo $4^{\circ}$ inciso $\mathrm{V}$, estabelece como um dos princípios, a divulgação ampla dos benefícios, programas e projetos assistenciais, bem como os recursos demandados pelo poder público e os critérios para sua concessão. No entanto, as publicações com que a sociedade se depara dão conta apenas de quanto o governo deixa de arrecadar referente à isenção da contribuição previdenciária concedida às entidades filantrópicas. É completamente desconhecido o paradeiro dos relatórios encaminhados pelas entidades ao CNAS sobre os serviços prestados e as pessoas beneficiadas.

As entidades filantrópicas fazem parte do chamado terceiro setor, definido por Fernandes (1994) como sendo o conjunto de iniciativas particulares com um sentido público. Segundo o autor, o terceiro setor supõe um primeiro e um segundo, e nessa medida faz referência ao Estado e ao mercado. A referência, no entanto, é indireta, obtida pela negação - nem governamental, nem lucrativo.

Através do texto de Szazi (2000), pode-se deduzir que o primeiro setor é o que está sob a responsabilidade exclusiva do Estado, e o segundo setor são todas as empresas em geral, cuja função social é limitada ao pagamento de impostos, geração de empregos e, mais recentemente, a proteção do patrimônio ecológico. Seguindo essa orientação, as entidades filantrópicas situam-se no campo dos agentes não governamentais com o encargo de substituir o Estado no atendimento da educação, saúde e assistência social.

Toda entidade sem fins lucrativos que objetive a promoção da pessoa humana, mesmo não possuindo o Certificado de Entidade de Assistência Social é uma entidade filantrópica de fato, por aquilo que realiza. A educação, a saúde ou a assistência social, quando prestadas de forma gratuita, se constituem em atividades filantrópicas. As entidades que se dispõem a participar no atendimento a essas necessidades básicas, obedecendo aos requisitos legais, cobrando-os ou não, estão, automaticamente, tirando do Estado o ônus de fazê-lo e por esse motivo recebem tratamento diferenciado das demais empresas ou atividades. Porém, mesmo tendo as entidades idênticas finalidades, o tratamento do Estado é 
diferenciado, provocando uma divisão em filantrópicas e não-filantrópicas. O diferencial é o próprio Certificado.

A Resolução do Conselho Federal de Contabilidade - CFC n. ${ }^{\circ} 877$, em sua norma NBC T-10, define as entidades sem finalidade de lucro como sendo aquelas em que o resultado positivo não é destinado aos detentores do patrimônio líquido e que elas exercem atividades assistenciais, de saúde, educacionais, técnico-científicas, esportivas, religiosas, políticas, culturais, beneficentes, sociais, de conselhos de classe e outras, administrando pessoas, coisas e interesses coexistentes e coordenados em torno de um patrimônio, com finalidade comum ou comunitária.

O Estado, através do CNAS e com base em exigências legais, declara, para fins de direito, a natureza filantrópica da entidade. Em outras palavras, o Estado torna público, através de Ato Declaratório, o seu reconhecimento pelas atividades desenvolvidas por determinada entidade, que perante ele comprovou suas ações filantrópicas. Entretanto, o fato de não obter esse Ato Declaratório, não quer dizer que a entidade não seja efetivamente uma entidade filantrópica. A filantropia não está no Ato Declaratório, mas no humanitarismo, na assistência social e na gratuidade dos serviços prestados pela entidade através de seus associados e pessoas que impulsionam a vida da instituição. Assim, são as atividades de uma instituição sem fins lucrativos que a torna uma entidade filantrópica de fato; o Certificado de Entidade de Assistência Social a torna também uma entidade filantrópica de direito.

\section{ASPECTOS LEGAIS CONTESTÁVEIS}

De acordo com a LOAS, art.1 ${ }^{\circ}$, a assistência social, direito do cidadão e dever do Estado, realizada através de um conjunto integrado de ações de iniciativa pública e da sociedade, para garantir o atendimento às necessidades básicas. Fica claro, portanto, que o atendimento às necessidades básicas é direito do cidadão e dever do Estado, sem questionamento sobre a classe social a que ele pertence. 
Consta na Constituição Federal (1988), em seu art.150, inciso VI que, sem prejuízo de garantias asseguradas ao contribuinte, é vedado à União, aos Estados, ao Distrito Federal e aos Municípios, instituir imposto sobre o patrimônio, a renda ou os serviços de templos de qualquer culto, das instituições de educação e de assistência social sem fins lucrativos, dos partidos políticos e suas fundações e das entidades sindicais dos trabalhadores, atendidos os requisitos da lei. Pelo texto, pode-se concluir que a imunidade não atinge apenas as entidades filantrópicas, mas todas as entidades que possuem fins sociais e não lucrativos. Os requisitos aos quais estão sujeitas essas instituições, para garantirem a imunidade, são definidos pelo Código Tributário Nacional - CTN (2001), em seu art.14, e são os seguintes:

I - não distribuírem qualquer parcela de seu patrimônio ou de suas rendas, a qualquer título;

II - aplicarem integralmente, no País, os seus recursos na manutenção dos seus objetivos institucionais;

III - manterem escrituração de suas receitas e despesas em livros revestidos de formalidades capazes de assegurar sua exatidão.

O Decreto No 2.536 (1998), Art. $3^{\circ}$, determina que faz jus ao Certificado de Entidade de Fins Filantrópicos a entidade beneficente de assistência social que demonstre, nos três anos imediatamente anteriores ao requerimento, cumulativamente:

I - estar legalmente constituída no País e em efetivo funcionamento;

II - estar previamente inscrita no Conselho Municipal de Assistência Social do município de sua sede, se houver, ou no Conselho Estadual de Assistência Social;

III - estar previamente registrada no Conselho Nacional de Assistência Social - CNAS;

IV - aplicar suas rendas, seus recursos e eventual resultado operacional integralmente no território nacional e na manutenção dos seus objetivos institucionais;

$V$ - aplicar as subvenções e doações recebidas nas finalidades a que estejam vinculadas;

VI - aplicar anualmente, em gratuidade, pelo menos vinte por cento da receita bruta proveniente da venda de serviços, acrescida da receita decorrente de aplicações financeiras, locação de bens, de venda de bens não integrantes do ativo imobilizado e de doações particulares, cujo montante nunca será inferior à isenção das contribuições sociais usufruídas; 
VII - não distribuir resultados, dividendos, bonificações, participações ou parcela do seu patrimônio, sob nenhuma forma ou pretexto;

VIII - não perceberem seus diretores, conselheiros, sócios, instituidores, benfeitores ou equivalentes, remuneração, vantagens ou benefícios, direta ou indiretamente, por qualquer forma ou título, em razão das competências, funções ou atividades que Ihes sejam atribuídas pelos respectivos atos constitutivos;

IX - destinar, em seus atos constitutivos, em caso de dissolução ou extinção, o eventual patrimônio remanescente a entidades congêneres registradas no CNAS ou a entidade pública;

$X$ - não constituir patrimônio de indivíduo ou de sociedade sem caráter beneficente de assistência social.

Percebe-se que, para ser filantrópica os requisitos não são os mesmos, mas principalmente, não são apenas aqueles exigidos pela Constituição Federal e pelo Código Tributário Nacional. Fica evidente que há dois tipos de entidades imunes, umas filantrópicas e outras não.

No Brasil, a maioria das instituições religiosas de educação são também entidades de assistência social e, conseqüentemente, filantrópicas, pois a preocupação com o próximo nessas instituições, deve-se reconhecer, é mais antiga do que no próprio Estado. Essa situação é plenamente legal e constitucional. Entretanto, cria inúmeras dificuldades no campo administrativofinanceiro, fiscal, tributário e contábil.

A razão que levou as instituições de assistência social a buscarem o reconhecimento de utilidade pública e de entidade de fins filantrópicos foi a obtenção da isenção da quota patronal de previdência social, que só é concedida a Entidades Filantrópicas. É por esse motivo que todas as entidades de assistência social são ou almejam ser filantrópicas, caracterizando-se mais uma divisão das entidades: as imunes e as imunes e também isentas. Enquanto não puderem ser filantrópicas, são apenas imunes.

Aqui já se pode perceber a primeira grande falha legislativa, o que desencadeia, conseqüentemente, ações do Estado completamente distintas. Por delegação do CNAS, as entidades filantrópicas são fiscalizadas pelo Instituto Nacional de Seguridade Social - INSS, através de seus fiscais e auditores, os 
quais se empenham em descaracterizar a condição de filantrópica das entidades para voltar a arrecadar a parcela isenta de contribuição previdenciária. As outras entidades não são fiscalizadas, tendo como única preocupação a renovação do atestado de utilidade pública, concedido mediante a comprovação de algumas ações de cunho social sem parâmetros definidos.

Portanto, basta atender aos requisitos do CTN para que as entidades de educação, de saúde ou de assistência social sejam imunes de qualquer imposto, caracterizando um obstáculo constitucional que limita ao Poder Público a competência de tributar, criado por uma norma da Constituição que impede a incidência de lei ordinária de tributação sobre determinado fato. O art.16 do CTN define o imposto como sendo o tributo cuja obrigação tem por fato gerador uma situação independente de qualquer atividade estatal específica, relativa ao contribuinte. Sobre a isenção, o CTN, em seu art. 97, inciso VI, diz que ela é sempre decorrente de lei e está incluída na área da denominada reserva legal, sendo a lei, em sentido estrito, o único meio hábil para sua instituição, havendo a necessidade de legislação complementar, suprida pelos Decretos 2.536 (1998) e Decreto 3048 (1999).

É de conhecimento público que ainda existem no Brasil inúmeras entidades filantrópicas, criadas exclusivamente com a finalidade de usufruir os benefícios da filantropia, sem nenhuma função social definida que, pouco a pouco, estão sendo fiscalizadas e desqualificadas. Porém, a ação do CNAS, inclusive nessas entidades, se limita a renovar ou cancelar o Certificado de Entidade de Assistência Social, podendo remeter as mesmas de volta à condição de imune apenas, se constatado o não atendimento aos requisitos para a filantropia. A partir daí, essas entidades estão livres e podem até sobreviver sem desenvolver funções sociais significativas. Mas terão a imunidade, o que não é pouco considerando a carga tributária do país, constituindo-se na segunda falha legislativa a ser considerada.

Para substituir o Estado, a preocupação das entidades filantrópicas deve centrar-se sempre naquilo que o próprio Estado faria, ou seja, fazer aquilo que melhor possa promover seus destinatários ou seus assistidos, justificando sua 
condição de entidade de utilidade pública, entidade de fins filantrópicos, entidade paraestatal, de fim público ou de bem comum. Entretanto, no decorrer dos últimos tempos, as entidades começaram a perceber que ser de utilidade pública e ter o reconhecimento de entidade filantrópica é gerar comprometimentos com o governo. É o Estado interferindo em suas atividades, tirando-lhe a liberdade de agir, inclusive estabelecendo critérios, na prestação de serviços, diferentemente do que ele próprio faz. A prestação de serviços pelo Estado não discrimina as pessoas de acordo com a classe social a que pertencem. O mesmo critério é condição para o fornecimento do Certificado de Entidade de Fins Filantrópicos, através do Decreto 2.536 (1998) em seu Art. $3^{\circ}$, inciso X, $\$ 1^{\circ}$, o qual determina que somente será fornecido o Certificado de Entidade de Assistência Social à entidade cuja prestação de serviços gratuitos seja permanente e sem qualquer discriminação de clientela. Porém, o Decreto № 3048 (1999), que regulamenta a concessão de isenção de contribuições, estabelece que:

\section{Art.206. Fica isenta das contribuições a entidade que (...)}

IV - promova, gratuitamente, a assistência social beneficente a pessoas carentes, em especial a crianças, adolescentes, idosos e portadores de deficiência;

$\S 2^{\circ}$ Considera-se pessoa carente a que comprove não possuir meios de prover a própria manutenção, nem tê-la provida por sua família.

Verifica-se aqui a terceira falha legislativa. No que se refere aos destinatários dos benefícios, o Estado, em não discriminando a clientela, atende gratuitamente pessoas que poderiam pagar pelos serviços, enquanto que as entidades de assistência social não podem fazê-lo. No caso de entidades de educação, a gratuidade concedida a pessoas que não comprovarem carência, em qualquer percentual, é desprezada. No entanto, se o Estado o faz, é atendimento gratuito. Seria prudente considerar, em situações como esta, o que é mais vantajoso ao Estado: deixar que as entidades concedam alguma gratuidade, ou, assumir $\mathrm{o}$ atendimento.

A partir de 1994, o CNAS, na função de administrador dos serviços de assistência social, passou a exigir comprovação, cada vez mais detalhada, sobre a efetiva participação das entidades filantrópicas no processo de assistência social 
dentro das áreas de atividade de cada uma. Por esse motivo, atualmente elas são obrigadas, por força de normas legais, a cumprir uma série de exigências que limitam sua liberdade administrativa que podem inviabilizar o seu funcionamento. A questão mais crítica reside na elevada parcela de assistência social exigida para fazer jus à condição de filantrópica, mesmo sendo efetivamente entidade de assistência social.

A Constituição Federal, em seu art.195, § 7.', diz que são isentas de contribuição para a seguridade social as entidades beneficentes de assistência social que atendam às exigências estabelecidas em lei. Porém, Legislações complementares sobre as isenções condicionam o benefício somente às entidades portadoras do Certificado de Entidade de Assistência Social, ou seja, às Entidades Filantrópicas. O preceito legal, mesmo discutível, é aplicado para as entidades e, quando indeferido o pedido de renovação do Certificado e não havendo interposição de ação judicial, a contribuição previdenciária passa a ser cobrada.

Com muita propriedade, a Constituição Federal (2001), em seu art. 6. consagra como direitos sociais, entre outros, a educação e a saúde. O Estatuto da Criança e do Adolescente - ECA (1996), em seu art. 53, reforça que a criança e o adolescente têm direito à educação, visando ao pleno desenvolvimento de sua pessoa, preparo para o exercício da cidadania e qualificação para o trabalho. Portanto, enquanto o Estado não tiver condições de prover essas garantias às crianças e aos adolescentes, deve dar condições para que as entidades o façam.

É de fácil entendimento que nem toda entidade sem fins lucrativos é filantrópica e que o critério para se obter imunidade ou isenção não é a filantropia, mas sim a assistência social. A afirmativa adquire respaldo pelo fato de não haver qualquer referência a filantropia ou a entidade filantrópica na Constituição Federal e no Código Tributário Nacional. Talvez por esse motivo o Certificado de Entidade de Fins Filantrópicos (CEFF) tenha mudado para Certificado de Entidade Beneficente de Assistência Social (CEBAS), atualmente Certificado de Entidade de Assistência Social - CEAS, o qual não se faz necessário para que a entidade 
seja imune aos impostos, constituindo-se no único diferencial entre entidades imunes e entidades imunes e isentas de contribuições sociais.

As gratuidades concedidas pelas entidades filantrópicas da área da educação substituem as contribuições previdenciárias a que as mesmas estariam sujeitas. Em troca dessas contribuições sociais, de aproximadamente 25\% (vinte e cinco por cento) sobre a folha de pagamento, as entidades filantrópicas se submetem à prestação de assistência social no percentual de $20 \%$ (vinte por cento) sobre suas receitas de venda de bens ou serviços, excluídas as vendas de bens do ativo imobilizado, acrescidas das receitas provenientes de aplicações financeiras, aluguéis e doações particulares.

Conforme o Decreto 2.536 (1998), art. 3. ${ }^{\circ}, \mathrm{VI}$, as entidades de educação devem aplicar anualmente, em gratuidade, pelo menos vinte por cento da receita bruta, cujo montante nunca será inferior à isenção de contribuições sociais usufruídas. A falta de critérios no estabelecimento de percentuais e a exigência linear de $20 \%$ sobre a receita bruta são parâmetros injustos e caracterizam a quarta grande falha legislativa.

Exemplificando: se uma determinada entidade educacional possuir uma receita total bruta de $\mathrm{R} \$ 100.000,00$ (cem mil reais) mensais, e sua folha de pagamento montar $\mathrm{R} \$ 90.000,00$ (noventa mil reais) mensais, sua obrigação de gratuidade será, conforme legislação específica, no mínimo o valor da isenção usufruída, nesse caso $\mathrm{R} \$ 22.500,00$ (vinte e dois mil e quinhentos reais), o que representa $25 \%$ sobre a folha de pagamento e não os $20 \%$ (vinte por cento) sobre a receita bruta que seria $R \$ 20.000,00$ (vinte mil reais). Na prática, permanecendo o critério atual, as entidades que não tiverem condições de gerar receita são penalizadas com o percentual maior.

Por outro lado, se uma entidade educacional possuir uma receita mensal bruta de $R \$ 100.000,00$ (cem mil reais) e a folha de pagamento de $R \$ 50.000,00$ (cinqüenta mil reais) mensais, o percentual de $20 \%$ (vinte por cento) sobre a receita bruta, equivale a $40 \%$ (quarenta por cento) sobre a folha de pagamento, ou seja, $\mathrm{R} \$ 20.000,00$ (vinte mil reais). Neste caso, é preferível pagar os encargos sociais, que seriam de $R \$ 12.500,00$ (doze mil e quinhentos reais). Acerca dessa 
situação, há de ser respondido um questionamento: sem entrar no mérito da qualidade dos serviços prestados, seria o governo capaz de executar o mesmo serviço que a referida entidade faria, com os mesmos recursos provenientes das contribuições previdenciárias cobradas?

O caso das entidades de saúde é mais crítico ainda. De acordo com o Decreto $n^{\circ} 2.536$ (1998), elas devem comprovar, anualmente, percentual de atendimento decorrente de convênio firmado com o Sistema Único de Saúde SUS, igual ou superior a sessenta por cento do total de sua capacidade instalada. Esse critério, também definido pelo CNAS, funcionou relativamente bem por algum tempo, mas que atualmente, devido aos fatores econômicos em geral, estão cada vez mais difíceis de serem cumpridos pelos hospitais. Na prática, o que se constata é que os sessenta por cento dos leitos destinados ao SUS estão sempre lotados e os outros quarenta por cento, reservados a clientes que teoricamente deveriam sustentar todo o hospital, estão migrando para o sistema único, despovoando essa área, já que o Estado, conforme frisado, não discrimina pobres ou ricos e se obriga a conceder atendimento gratuito a quem solicitar. A partir dessa mudança de atitude dos clientes, as entidades de saúde começaram a ver comprometida sua situação financeira, agravada ainda mais pelos valores irrisórios e em atraso repassados pelo Estado através do convênio SUS.

A mudança no comportamento da clientela dos hospitais encontra explicação devido à condição socioeconômica a que foi submetida a maioria da população brasileira, cujo orçamento familiar vem sendo reduzido gradativamente. Também as empresas em geral, antes acostumadas a projetar altas margens de lucros, hoje se condicionam a praticar percentuais que possam garantir a sua sobrevivência apenas, num mercado globalizado cuja concorrência é cada vez mais acirrada.

A primeira reação das entidades de saúde foi a de reduzir os custos. Porém, essa estratégia, relativamente fácil de ser implementada, chegou a um limite mínimo para o funcionamento, sendo praticamente impossível reverter a situação de comprometimento das receitas apenas com ela. Tornou-se imperiosa a opção de aumentar os preços. Mas, como aumentar os valores do SUS? Por 
mais necessário que seja esse aumento, não há negociações com o governo. E se houvesse, para cada unidade hospitalar o valor seria diferente, pois as características de cada uma, e conseqüentemente os custos, são diferentes. A última saída a ser considerada seria o aumento do valor dos serviços prestados aos clientes pagantes, ou seja, aquela mesma parcela disposta às internações na área representativa dos quarenta por cento, que o SUS permite, sejam utilizados para atendimento a pacientes particulares ou pagantes. Mas, desses clientes, muitos possuem outros convênios com empresas de saúde tipo unimed e outras, que também não aceitam aumentos sem negociação prévia. O restante dos clientes, além de não considerar simpática a proposta, poderá ter aí um motivo derradeiro para optar pelo atendimento gratuito, admitindo a redução da qualidade a comprometer o orçamento familiar.

Esta situação caótica a que chegaram as entidades, muitas das quais já fecharam suas portas, deve-se, em grande parte, à exigência do cumprimento dos requisitos para a renovação do Certificado de Entidade de Assistência Social. Apenas os hospitais dos grandes centros ou pertencentes a grandes redes ainda conseguem administrar ou conviver com o caos instalado. Aqueles situados no interior dos estados e pertencentes a pequenas entidades ou a associações comunitárias estão com os dias contados. Por outro lado, o que se verifica nos hospitais públicos é outro tipo de caos: as estruturas não estão mais suportando o fluxo de pacientes, sujeitando-os ao atendimento em macas improvisadas nos corredores, isso quando alguma estiver disponível. Na entrada de emergência, ambulâncias se aglomeram desde as primeiras horas da manhã, vindas das localidades onde hospitais foram fechados.

A inquietação da sociedade também contempla o questionamento sobre a inexistência de informações sobre os auxílios concedidos a hospitais para o suprimento de dificuldades financeiras. No entanto, sabe-se de polpudas somas destinadas ao socorro de instituições financeiras.

Para optarem pela filantropia, as entidades devem ter, obrigatoriamente, 0 título de utilidade pública, equiparando-se a um órgão público, pelos serviços que disponibiliza à comunidade nas diversas áreas específicas. A partir desse 
momento, o Estado passa a exigir e a população a não dispensar os referidos serviços, através delas, de suas substitutas ou, em último caso, através de um órgão público. Aqui encontra explicação o requisito legal do Decreto 2.536 (1998), o qual exige que, em caso de dissolução ou extinção, as entidades filantrópicas devem destinar seu patrimônio a uma entidade congênere ou a um órgão público. Conclui-se que o patrimônio de uma entidade filantrópica não está disponível a seus associados, mas à coletividade e ao governo, destinatários e fiscal respectivamente. Analisadas sob esse ângulo, as isenções poderão se constituir em um problema para as entidades que delas não se utilizarem com primor, pois, se de um lado estarão beneficiando-se, de outro estarão comprometidas para com o Estado, pois, ao contemplar-se com os incentivos fiscais estão deixando o seu estado liberal para dividir seus propósitos com o Estado que, além de fiscalizá-las, poderá vedar o seu funcionamento, pondo em risco o seu patrimônio e a sua própria existência e, por iniciativa do Ministério Público, vir a processar seus diretores e gestores, por indevida utilização de bem público.

Não resta a menor dúvida de que a situação ora vivenciada só começará a ter solução a partir de ações governamentais. Conforme demonstrado, a legislação existente está completamente fora da realidade atual, sugerindo mudanças radicais, de forma a reverter a tendência de fechamento da maioria dos hospitais privados.

\section{CONTABILIDADE DAS ENTIDADES FILANTRÓPICAS}

As entidades filantrópicas se caracterizam pelos serviços prestados, sendo eles o seu principal produto. De acordo com Vanderbeck (2001), um serviço é um benefício intangível, não possui propriedades físicas e é consumido no momento em que é fornecido. Os serviços prestados pelas Entidades Filantrópicas, pelas características mencionadas, deveriam ser lançados pelo regime de caixa, ou misto, pois sua cobrança, em parte considerável, é duvidosa. Enquanto as empresas que vendem produtos não perecíveis podem, eventualmente, obter de volta o bem alienado, as Entidades Filantrópicas, cuja 
inadimplência é significativamente alta, não podem fazê-lo, pois seria impossível fazer retornar serviço prestado.

A quinta falha legislativa é também fiscal, pois a legislação pertinente equipara as Entidades Filantrópicas com os órgãos públicos quanto à prestação dos serviços essenciais, como se públicas fossem. Nos órgãos públicos, a receita é lançada pelo regime de caixa, pelos mesmos motivos que geram a alta inadimplência nas Entidades Filantrópicas: há a certeza de que o serviço é disponibilizado à população, mas a cobrança é assunto praticamente desvinculado dele. No entanto, para as Entidades Filantrópicas é exigida a observação do princípio de competência, com apropriação e tributação, pela parcela de assistência social, de todas as possíveis receitas, no momento de seu faturamento. Não se faz necessário muito aprofundamento na área para concluir que há diferenciação no tratamento contábil.

Todas as falhas fiscais e algumas legislativas poderiam ser evitadas se fossem envolvidas no processo, técnicas apuradas de contabilidade gerencial, bem como profissionais capacitados da área contábil. Segundo Leone (1997), a contabilidade de custos é o ramo da contabilidade que se destina a produzir informações para os diversos níveis gerenciais de uma entidade, coletando, classificando e registrando os dados operacionais das diversas atividades, além de organizar, acumular, analisar e interpretar os indicadores combinados no sentido de produzir relatórios com as informações solicitadas. Portanto, a contabilidade, através de suas técnicas e especializações, pode contribuir

enormemente para o estabelecimento de critérios justos para o cálculo e o registro dos valores produzidos pelas entidades, de maneira a garantir a sobrevivência das mesmas e, conseqüentemente, a manutenção dos seus serviços à comunidade.

\section{VANTAGENS DA NÃO-FILANTROPIA}

Ao optar pela filantropia, as entidades abrem mão da propriedade de seu próprio patrimônio e passam a ser "parceiras" do Estado, com as mesmas atribuições quanto aos atendimentos, mas com cada vez menos condições de 
funcionamento, pelas freqüentes alterações da legislação, dificultando a consecução dos seus objetivos institucionais. Essa interpretação adquire fundamento no art. $3 .^{\circ}$, IX, do Decreto n. ${ }^{\circ}$ 2.536/98, que obriga a entidade a destinar, em seus atos constitutivos em caso de dissolução ou extinção, o eventual patrimônio remanescente a entidades congêneres registradas no CNAS ou a uma entidade pública.

No caso de uma instituição de ensino, para obter o Certificado de Entidade de Assistência Social (CEAS), há exagerada gama de requisitos a serem preenchidos, não deixando margem para dúvidas quanto à vocação da solicitante em ser uma "entidade de assistência social". Para a renovação do Certificado, as exigências são todas as já citadas e mais a prestação de contas sobre os últimos três exercícios, em que não pode a entidade ter despendido, em qualquer um deles, menos do que $20 \%$ (vinte por cento) de suas receitas em assistência social a "pessoas carentes", entendidas aquelas que não tenham condições de prover a própria sustentação, pertencentes a uma família com renda familiar em torno de dois salários-mínimos.

É nítida a discriminação. A perdurar essa sistemática, as entidades filantrópicas ficarão com a pobreza, e o Estado, que não discrimina pobres ou ricos, concederá matrículas aos que poderiam pagar.

Ainda na área da educação, nota-se que a condição socioeconômica das famílias brasileiras vem sendo afetada pela situação da economia nacional, e isso está provocando uma grande evasão escolar nas escolas privadas, em função do valor dos encargos educacionais. As estruturas que essas entidades montaram para a educação geram custos fixos elevados que são cada vez mais difíceis de serem suportados pelos, cada vez menos, alunos pagantes matriculados.

Porém o percentual de assistência social não diminui e se torna alvo inatingível. É pesado para quem optou por fazê-la. Considerando que também a margem de lucro das empresas brasileiras vem se reduzindo progressivamente, e fazendo-se uma análise coerente, é de se questionar: por que a inflexibilidade na taxa? Em quê desvirtuaria a ação filantrópica das entidades, um percentual de $15 \%$ (quinze por cento)? 
Sendo portadora do CEAS, há necessidade de comprovação da aplicação de vinte por cento a título de assistência social sobre os aluguéis, as doações recebidas e os juros auferidos nos investimentos. Se não for filantrópica, mas somente de educação ou de assistência social, observados os requisitos legais, só são devidas as Contribuições Sociais sobre essas mesmas receitas.

No mínimo, há de ser repensado esse parâmetro. Não deve o CNAS desmotivar as instituições, fazendo com que cheguem ao extremo de abrirem mão da condição de filantrópica, ou, o que é pior, "fechar as portas" pelas barreiras impostas às suas ações filantrópicas.

$E$ as dificuldades poderiam ter aumentado. A Lei n. ${ }^{\circ} 10.260$, de 12 de julho de 2001, suspensa por Ação de Inconstitucionalidade, preceituava, em seu artigo 19, que as entidades filantrópicas de educação seriam obrigadas a aplicar o equivalente à contribuição previdenciária na concessão de bolsas de estudo, somente em percentual igual ou superior a $50 \%$ (cinqüenta por cento) da mensalidade, a alunos comprovadamente carentes.

A interpretação do texto deixa claro que a intenção do legislador era de ampliar os atendimentos gratuitos e, mais uma vez, direcioná-los somente à população em situação de miséria. Mas não se pode negar que, a princípio, ela é justa e já era esperada. A evolução natural da legislação pressupõe a ampliação das exigências e a tendência de chegar ao que seria o máximo: as entidades filantrópicas educacionais deverão, em um futuro muito próximo, conceder bolsas de estudo integrais, a pessoas extremamente carentes, no percentual de $20 \%$ (vinte por cento) de seus alunos. Há de se convir que a burocracia diminuiria sensivelmente, pois não haveria necessidade da evidenciação de valores. A comprovação da aplicação em assistência social se resumiria em verificar o número de atendimentos. Se de um lado isso facilita a ação fiscalizadora do CNAS, por outro exige uma reestruturação das entidades. Não se pode atender, no mesmo local, alunos carentes e alunos pagantes, como forma de evitar constrangimentos e, na ânsia de exigir e fazer o bem, criar um problema social.

As entidades deveriam criar novos ambientes para os novos atendimentos e isso também exige investimentos que podem não estar disponíveis. 
De acordo com a Resolução n. ${ }^{\circ} 177$ de 10/08/2000, art. 3. ${ }^{\circ}$, V, para usufruir dos benefícios fiscais da filantropia, a entidade deve fazer constar em seu estatuto social disposições que determinem que ela aplica suas receitas, rendas, rendimentos e o eventual resultado operacional integralmente no território nacional, na manutenção e no desenvolvimento de seus objetivos institucionais, não distribui resultados, dividendos, bonificações, participações ou parcela de seu patrimônio, sob nenhuma forma, nem constitui patrimônio de indivíduo ou de sociedade sem caráter de assistência social. Fazendo-se uma análise do texto pode-se entender, perfeitamente, que 100\% (cem por cento) dos recursos gerados pelas entidades filantrópicas são destinados à assistência social, seja em valores monetários ou em patrimônio à disposição da coletividade.

É por essas dificuldades e por falta de condições de se enquadrarem nos parâmetros rígidos do Conselho Nacional de Assistência Social que, aos poucos, as entidades filantrópicas estão se transformando em entidades econômicas, abrindo mão da filantropia e, automaticamente, recebendo de volta a propriedade incondicional de seus estabelecimentos, podendo fazer deles o que bem entenderem, inclusive transformá-los em shopping centers se assim o desejarem, de acordo com a localização, que, normalmente, é propícia ao ramo.

Em se tratando de Brasil, beira o absurdo o governo desprezar o auxílio de entidades para os serviços na área da assistência social. Pode-se perceber nos textos da legislação pertinente à filantropia, nas investidas dos legisladores, inclusive com textos declarados "inconstitucionais", a nítida intenção de extinguir as entidades filantrópicas. Os questionamentos agora são outros: acaso existe legislação responsabilizando essas pessoas pelo dano que podem causar a quem realmente é o beneficiário da assistência social? Será que, extinguindo essas entidades, o governo, com os mesmos recursos que passa a cobrar, pode fazer mais ou melhor?

A ação social está mais na opção pelos necessitados do que pela filantropia. E, quando as atuais "carregadoras de piano" sentirem o fardo muito pesado a quem devem recorrer? Há preocupação de parte do governo sobre sua sobrevivência ou não? O que o CNAS fará, quando não existirem mais entidades 
filantrópicas? Será que o governo conta como certa a mobilização da população em criar entidades com abnegados "parceiros voluntários" que possam substituir as atuais entidades filantrópicas sem que sejam necessários recursos para prestar os mesmos atendimentos?

\section{AÇÃO FISCALIZADORA DO ESTADO}

De acordo com a Lei $n^{\circ}$ 8.742, de 07 de dezembro de 1993, o CNAS é o órgão da Administração Pública Federal responsável pela coordenação da Política Nacional de Assistência Social e órgão superior de deliberação colegiada, de caráter permanente do sistema descentralizado e participativo da Assistência Social, de composição paritária entre governo e sociedade civil e uma de suas competências é fixar normas para a concessão de registro e certificado de entidade de fins filantrópicos às entidades privadas prestadoras de serviços e assessoramento de assistência social.

Cabe ao CNAS fiscalizar a ação das entidades filantrópicas sem interferir em seu funcionamento e, nos limites constitucionais, punir aquelas instituições que desvirtuam as finalidades a que foram constituídas, mas nunca referir-se a elas sob a presunção de que todas são desonestas.

E quando se trata de punição, a única maneira de punir utilizada pelo CNAS é o indeferimento ao pedido de renovação do Certificado de Entidade de Assistência Social (CEAS), com base em parecer emitido pela fiscalização do INSS, órgão comprometido apenas em formar fundos para a manutenção de um sistema falido de previdência social. Pode-se esperar qualquer coisa desta fiscalização, menos elogios às ações desenvolvidas. Às entidades resta depositar confiança no CNAS para que este consiga, com muito bom senso, transformar um relatório de fiscalização que só enumera defeitos e possíveis pontos falhos, em um instrumento de decisão para a preservação das entidades e dos serviços de assistência social.

Deve-se entender que o importante não são as gratuidades financeiras ou econômicas concedidas, mas a ação filantrópica promotora dos serviços à 
sociedade. As entidades filantrópicas colaboram com o mesmo esforço do Estado na erradicação das diferenças sociais. Seu papel é de complementar as atividades do Estado, em vista de sua ineficiência, de sua incapacidade em poder atingir com plenitude as efetivas finalidades sociais.

Ao Estado não deve interessar a quantidade de gratuidades economicamente avaliadas, mas a ação social, através dos serviços que são prestados pelas entidades filantrópicas. Fazer filantropia é colocar o homem como centro de sua própria história.

As ações do Estado que trariam melhores resultados, sem dúvida, seriam as de "promover" a abertura de novas entidades filantrópicas, como forma de garantir os atendimentos e mesmo os espaços para as áreas da educação, saúde e assistência social.

Enquanto o Estado não pode fazer sozinho aquilo de que a comunidade necessita, deve ter a humildade de reconhecer nas entidades filantrópicas, grandes aliados e merecedores de todas as atenções necessárias à sua sobrevivência e proliferação, zelando pela situação financeira dessas instituições, nas dificuldades de instalação e início de funcionamento. Quanto mais e maiores forem as entidades, melhor.

\section{ABRANGÊNCIA DA AÇÃO SOCIAL}

O Art. 86 do Estatuto da Criança e do Adolescente define que "a política de atendimento dos direitos da criança e do adolescente far-se-á através de um conjunto articulado de ações governamentais e não governamentais, da União, dos Estados, do Distrito Federal e dos Municípios".

As entidades de educação, de assistência social e de saúde, registradas de forma a atenderem aos requisitos do art.14 do Código Tributário Nacional, constituem auxílio aos órgãos públicos na obtenção dos direitos básicos preceituados na Constituição Federal e no Estatuto da Criança e do Adolescente. 
Porém, para que a ação social dessas entidades seja significativa, é necessário que elas gerem recursos através de suas atividades, ou os recebam dos diversos órgãos e lhes prestem conta periodicamente.

Os recursos provenientes da União, Estados ou Municípios para aplicação na área social são cada vez mais escassos, pois há prioridades, muitas vezes políticas, dificultando a obtenção e liberação dos mesmos.

Poder-se-ia pensar em tornar públicos todos os estabelecimentos e atendimentos nas áreas da assistência social, a exemplo de alguns países. Mas no Brasil, onde a tônica foi a privatização, como forma de evitar prejuízos, é pouco provável que a sociedade acredite que isso possa funcionar a contento.

Com o intuito de suprir as dificuldades governamentais é que as entidades filantrópicas devem desenvolver suas ações sociais, direcionando-as principalmente aos mais necessitados, consolidando sua posição de coresponsáveis pela assistência social.

\section{CONCLUSÃO}

A solução dos impasses criados em torno da filantropia e das entidades filantrópicas só será possível quando houver conscientização sobre a necessidade de governo e sociedade visarem a um objetivo comum: a assistência social, seja na educação, na saúde ou no atendimento de outras necessidades básicas da população. As mudanças na legislação se fazem necessárias para que as entidades encontrem uma forma de se adequarem às mesmas.

As entidades filantrópicas podem ser de vital importância para atingir esse objetivo, visto que a maioria delas contempla em seus estatutos a prestação de serviços à coletividade, nas diversas áreas, constituindo-se em um inestimável auxílio ao Estado no cumprimento de suas obrigações com a população mais carente. Essas entidades não podem querer apenas eximir-se das contribuições. Elas devem prestar assistência social efetiva, de qualidade e direcionada a quem realmente necessita, em troca do benefício da isenção. Juntamente com o governo, elas devem zelar por uma sociedade justa e uma população sem 
dificuldades. Para continuarem existindo e até proliferarem, as entidades filantrópicas precisam ser desejadas, ou, no mínimo, valorizadas por aquilo que fazem e pelo muito que ainda podem fazer. Em outras palavras, é preciso que o governo deixe de perseguir e comece a apoiar as iniciativas dessas entidades.

Diante dos fatos evidenciados, cabe ao governo repensar toda a legislação sobre a assistência social de forma abrangente, sob pena de ter que arcar com toda ela. Hoje os legisladores podem pensar que as dificuldades das entidades é problema apenas delas. Amanhã, a sociedade poderá ter o suprimento da assistência social unicamente via atendimento gratuito, com a costumeira baixa qualidade, mas público, pela inexistência de outras opções.

Quanto à ação fiscalizadora do CNAS, é preciso que o mesmo se volte para a verificação sobre o cumprimento dos requisitos básicos atendidos pelas entidades, principalmente constatar se elas possuem vocação para ser filantrópicas, punindo os infratores, mas preservando a imagem das entidades que são, comprovadamente, de assistência social.

Há uma carência enorme de orientações às entidades quanto à melhor maneira de desenvolver as ações sociais e, quando consultado, o CNAS informa que há legislação em vigor. Porém conforme o exposto, a legislação é contraditória e deixa muitas dúvidas, dando margem a interpretações que normalmente só são esclarecidas após a entrega dos relatórios das atividades desenvolvidas.

Para garantir o funcionamento das entidades filantrópicas, seria mais justo - e mais lógico - exigir delas o cumprimento daqueles requisitos básicos e, como aplicação em assistência social, no mínimo, o valor da contribuição previdenciária usufruída, em serviços colocados à disposição de pessoas carentes. Qualquer ampliação das exigências deve ser gradativa e não retroativa para aquelas que operam no limite máximo de suas possibilidades. Também como forma de resguardar a imagem dessas tão necessárias entidades, fazer publicar nos diversos meios de comunicação as informações sobre as ações que foram desenvolvidas pelas entidades em contrapartida às isenções concedidas. A permanecer a legislação atual em que o valor despendido pelas entidades 
filantrópicas para a assistência social é bem superior ao valor das contribuições previdenciárias devidas, independentemente de elas terem gerado lucro ou prejuízo, o quadro atual tenderá ao agravamento, inviabilizando o funcionamento dessas tão necessárias entidades. A conclusão a que se chega mais se aproxima da injustiça legal do que da justiça social.

\section{BIBLIOGRAFIA}

BRASIL. Decreto Nº 2.536 de 06 de abril de 1998. Brasília.

BRASIL. Decreto No 3.048 de 06 de maio de 1999. Brasília.

BRASIL. Lei N8.742 de 07 de dezembro de 1993. Brasília.

BRASIL. Lei №10.260 de 12 de julho de 2001. Brasília.

BRASIL. Resolução n 177 de 10 de agosto de 2000. Brasília.

BRASIL. Lei N 5.172. Código Tributário Nacional. São Paulo: Saraiva, 2001.

CONSELHO FEDERAL DE CONTABILIDADE. Resolução n. 877 de 18 de abril de 2000, NBC T-10. 2001. Brasília.

Constituição da República Federativa do Brasil. São Paulo: Saraiva, 2001.

Estatuto da Criança e do Adolescente. Santa Maria: Pallotti, 1996.

FERNANDES, Rubem César. Privado porem Público: o terceiro setor na América Latina. 2. ed. Rio de Janeiro: Dumará, 1994.

LEONE, George G. Gestão Estratégica de Custos, 5 ed. São Paulo: Atlas, 1997. LOAS: Lei Orgânica da Assistência Social - Brasília: MPAS, 1997.

POZZOBON, E.A. A filantropia - uma ação gratuita de associações constituídas e legisladas pelo Código Civil, sob a proteção da constitucionalidade da constituição: Santa Maria: Pallotti, 2003.

SZAZI, Eduardo, Terceiro setor: regulação no Brasil. São Paulo: Peirópolis, 2000.

VANDERBECK, Edward J.; NAGY, Charles F. Contabilidade de Custos. 11 ed. São Paulo: Pioneira Thompson Learning, 2001. 